\title{
OPEN Methylene blue can act as an antidote to pesticide poisoning of bumble bee mitochondria
}

\author{
Mikhail Syromyatnikov ${ }^{1,2}$, Ekaterina Nesterova ${ }^{1,2}$, Tatiana Smirnova $^{1}$ \& Vasily Popov ${ }^{1,2}$
}

The population of bumble bees and other pollinators has considerably declined worldwide, probably, due to the toxic effect of pesticides used in agriculture. Inexpensive and available antidotes can be one of the solutions for the problem of pesticide toxicity for pollinators. We studied the properties of the thiazine dye Methylene blue (MB) as an antidote against the toxic action of pesticides in the bumble bee mitochondria and found that MB stimulated mitochondrial respiration mediated by Complex I of the electron transport chain (ETC) and increased respiration of the mitochondria treated with mitochondria-targeted (chlorfenapyr, hydramethylnon, pyridaben, tolfenpyrad, and fenazaquin) and non-mitochondrial (deltamethrin, metribuzin, and penconazole) pesticides. MB also restored the mitochondrial membrane potential dissipated by the pesticides affecting the ETC. The mechanism of MB action is most probably related to its ability to shunt electron flow in the mitochondrial ETC.

A decline in the population of pollinators is a serious worldwide problem ${ }^{1-5}$ that has become a question of humankind biological safety. Bumble bees are among the most important pollinators ${ }^{6}$ that are also commonly used in agriculture (Bombus impatiens, Bombus ignitus, and Bombus terrestris) ${ }^{7}$. The populations of bumble bees have considerably declined in the North America, Europe, and other world regions ${ }^{8-10}$, presumably because of the toxic effects of pesticides ${ }^{11-14}$. The reasons for the loss of pollinating insects include habitat destruction ${ }^{15-17}$, various pathogens, e.g., such as viruses ${ }^{18,19}$ and Varroa mite ${ }^{20-22}$, climate change ${ }^{23-25}$, reduced food supply ${ }^{26-28}$, and global use of pesticides ${ }^{21,23,26,27,29,30}$. The synergistic effect of pesticides and pathogens may be the a major factor in the global decline of pollinators ${ }^{30,31}$. Among pesticides neonicotinoids are often blamed for the loss of bees $^{32,33}$, whereas fungicides can promote the effect of these pesticides on pollinators ${ }^{34-37}$. Pesticides affect insect reproduction, behavior, and development of bumble bee colonies ${ }^{38}$. Thus, pesticides are believed to the most significant deleterious factor in the colony collapse disorder ${ }^{39}$.

Some pesticides target mitochondria and reduce the efficiency of oxidative phosphorylation, e.g., by inhibiting the electron transport chain (ETC) complexes. For example, insecticide hydramethylnon inhibits the activity of Complex $3^{40,41}$. Insecticides/acaricides fenazaquin ${ }^{24}$, tolfenpyrad, and pyridaben ${ }^{42,43}$ inhibit Complex 1 . Some pesticides, e.g., pro-insecticide chlorfenapyr, uncouple oxidative phosphorylation in the mitochondria, which reduces the efficiency of this process and leads to the energy loss in the cells ${ }^{44}$.

Many non-mitochondrial pesticides can also affect the activity of mitochondria. Fungicide Pristine ${ }^{\circledR}$ inhibits mitochondrial function in honeybees ${ }^{45}$. Fipronil and imidacloprid influence multiple functional parameters of bee mitochondria and reduce the activity of these organelles ${ }^{46}$. Organophosphate pesticides often cause oxidative stress and mitochondrial dysfunction ${ }^{47}$. Pyrethroids can impair various mitochondrial functions, disrupt formation of the mitochondrial membrane potential, increase production of reactive oxygen species, alter the fluidity of the mitochondrial membrane lipids, and cause the damage of mitochondrial DNA ${ }^{48}$. Organochloride pesticides also can damage mitochondria ${ }^{49}$. For example, thiacloprid alters transcription of genes associated with oxidative phosphorylation ${ }^{50}$. Some fungicides inhibit mitochondrial respiration and uncouple oxidative phosphorylation in the bumble bee flight muscles ${ }^{51}$.

At the same time, improving mitochondrial functions can reduce the toxic effect of non-mitochondrial pesticides on bumble bees ${ }^{52}$. Hence, the use of inexpensive and available antidotes against pesticides can be one of the solutions for the problem of pesticide toxicity in pollinators, first of all, bumble bees and honey bees. However, the

${ }^{1}$ Department of Genetics, Cytology and Bioengineering, Voronezh State University, Voronezh, Russia 394018. ${ }^{2}$ Laboratory of Metagenomics and Food Biotechnology, Voronezh State University of Engineering Technolgies, Voronezh, Russia 394036. ${ }^{\circledR}$ email: syromyatnikov@bio.vsu.ru 
number of such antidotes is very limited. It was found that glucocorticoids and cyclophosphamide significantly alleviate the toxic effects of paraquat, an efficient herbicide used worldwid ${ }^{53}$. Sucralfate ${ }^{54}$ and ellagic acid ${ }^{55} \mathrm{can}_{\text {also }}$ prevent the toxicity of paraquat. Lysine acetylsalicylate significantly decreases paraquat toxicity in mammals ${ }^{56}$.

Atropine alleviates pesticide poisoning ${ }^{57-60}$, while oximes act as antidotes against specific pesticides ${ }^{59,61-63}$. Magnesium sulfate can be used for managing the poisoning with organophosphorus pesticides ${ }^{64}$ and aluminum phosphide $^{65}$. Pralidoxime and vitamin $\mathrm{K}$ are antidotes of organophosphorus insecticides and anticoagulant rodenticides, respectively ${ }^{66} .1,8$-Naphthalic anhydride is a potential antidote against fungicides ${ }^{67}$. Ozone, both in its gaseous form and dissolved in water, can be used to remove difenoconazole and linuron from carrots ${ }^{68}$.

Methylene blue (MB) is a thiazine dye that has recently attracted a significant attention of researchers because of its newly discovered biological activities. It was found that MB has an antidote effect in methemoglobinemia ${ }^{69,70}$ and poisoning with carbon monoxide and cyanide ${ }^{71,72}$. In the mitochondria, MB plays an important role due to its activity as a catalytic redox cycler ${ }^{73}$ and can serve as an alternative electron acceptor ${ }^{74}$. $\mathrm{MB}$ was found to improve mitochondrial respiration and to decrease oxidative stress in the hearts of diabetic rats $^{75}$, as well as to maintain the function and structure of the retina treated with rotenone (Complex 1 inhibitor ${ }^{76}$. It also inhibits multiple amine oxidases, thereby preventing chloroacetaldehyde formation. Taking into account the above properties of $\mathrm{MB}$, we believe that $\mathrm{MB}$ can be used as an antidote to a wide range of pesticides affecting animals, including pollinators. An important advantage of $\mathrm{MB}$ is that it can be added to the syrup fed to bumble bees.

Here, we studied the properties of $\mathrm{MB}$ as a potential antidote against the toxic effects of pesticides. To evaluate the protective effect of $\mathrm{MB}$, we measured mitochondrial respiration and membrane potential of the bumble bee mitochondria subjected to the action of various pesticides and treated with MB.

\section{Materials and methods}

Bumble bees. B. terrestris (L.) males were provided by the Technology of Bumble Bee Rearing Ltd. (Voronezh, Russia). The bumble bees were kept in cylindrical cages (diameter, $14 \mathrm{~cm}$; height, $7 \mathrm{~cm}$ ) in the dark at $27-28.5^{\circ} \mathrm{C}$ at the air humidity of $55-68 \%$. The bumblebees were fed with $60 \%$ inverted sugar syrup.

Pesticides. Mitochondrial pesticides chlorfenapyr (CAS Number 122453-73-0), hydramethylnon (CAS Number 67485-29-4), pyridaben (CAS Number 96489-71-3), tolfenpyrad (CAS Number 129558-76-5), and fenazaquin (CAS Number 120928-09-8) and non-mitochondrial pesticides imidacloprid (CAS Number 13826141-3), deltamethrin (CAS Number 52918-63-5), malathion (CAS Number 121-75-5), metribuzin (CAS Number 21087-64-9), penconazole (CAS Number 66246-88-6), cypermethrin (CAS Number 52315-07-8), and esfenvalerate (CAS Number 66230-04-4) were from Sigma-Aldrich, USA. All pesticides were dissolved in dimethyl sulfoxide (DMSO) at a concentration of $10 \mathrm{mM}$.

Isolation of mitochondria. Bumble bee mitochondria were isolated as described earlier ${ }^{77}$. For each individual experiment, nine $B$. terrestris males were frozen at $-18{ }^{\circ} \mathrm{C}$ for $15 \mathrm{~min}$. The thoraces were separated from the heads and abdomens, placed in $12 \mathrm{ml}$ of ice-cold isolation medium (220 mM mannitol, $100 \mathrm{mM}$ sucrose, $1 \mathrm{mM}$ EGTA, $2 \mathrm{mg} / \mathrm{ml}$ fat-free BSA, $20 \mathrm{mM}$ HEPES, $\mathrm{pH}$ 7.4) and disintegrated with a 15-ml Dounce tissue grinder. All procedures were performed at $0-4{ }^{\circ} \mathrm{C}$. The homogenate was centrifuged for $5 \mathrm{~min}$ at $600 \mathrm{~g}$, and the supernatant was centrifuged for $10 \mathrm{~min}$ at $10,000 \mathrm{~g}$. The resulting pellet was resuspended in the washing medium (isolation medium without BSA) and centrifuged for $10 \mathrm{~min}$ at $10,000 \mathrm{~g}$. The pellet was resuspended in $100 \mu \mathrm{l}$ of the washing medium and kept on ice. Isolated mitochondria were used in the experiments within $2 \mathrm{~h}$ after isolation. Protein content in the mitochondria was determined with the BCA assay kit (Pierce Biotechnology, USA).

Mitochondrial respiration. The oxygen consumption rate (OCR) in the isolated mitochondria was measured by the amperometric method with a Clark oxygen electrode (Hansatech Instruments, USA). All measurements were performed at $24^{\circ} \mathrm{C}$ in $1 \mathrm{ml}$ of incubation medium containing $220 \mathrm{mM}$ mannitol, $100 \mathrm{mM}$ sucrose,

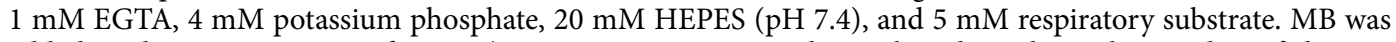
added to the concentration of $2 \mu \mathrm{M}$ ( $\mathrm{MB}$ concentration was chosen based on the earlier studies of the MB effect on the rat and mouse mitochondria ${ }^{78,79}$. The pesticides were directly added to the oxygraph chamber. The pesticide concentration in the oxygraph chamber was chosen to produce the maximum inhibitory effect (as previously determined for the mitochondrial respiration in vitro, unpublished data) and varied depending on the pesticide (Table 1). The effect of $\mathrm{MB}$ and each of the pesticides on mitochondrial respiration was measured in 6 repetitions $(n=6)$.

Membrane potential measurements. The membrane potential of the isolated mitochondria was evaluated from changes in the fluorescence of the membrane potential probe Safranin O using a Hitachi F-7000 spectrofluorometer (Hitachi, Japan) ${ }^{80}$ at the excitation wavelength of $495 \mathrm{~nm}$ and emission wavelength of $586 \mathrm{~nm}$. Incubation medium ( $1 \mathrm{ml}$ ) contained $220 \mathrm{mM}$ mannitol, $100 \mathrm{mM}$ sucrose, $1 \mathrm{mM}$ EGTA, $4 \mathrm{mM}$ potassium phosphate, $0.2 \mathrm{mg} / \mathrm{ml}$ BSA, $20 \mathrm{mM}$ HEPES ( $\mathrm{pH} 7.4$ ), 100-120 $\mu \mathrm{g}$ of mitochondrial protein, 2-4 nmol Safranin $\mathrm{O}$, and $10 \mathrm{mM}$ respiratory substrate. $\mathrm{MB}$ was added to the concentration of $2 \mu \mathrm{M}$. The pesticides were added directly to the cuvette; the pesticide concentration was the same as in the assessment of mitochondrial respiration (Table 1). The effect of MB and each of the pesticides on mitochondrial membrane potential was measured in 6 repetitions $(n=6)$. 


\begin{tabular}{|l|l|l|}
\hline Pesticide & Type & Concentration, $\boldsymbol{\mu M}$ \\
\hline Chlorfenapyr & Insecticide/mitochondrial & 30 \\
\hline Hydramethylnon & Insecticide/mitochondrial & 30 \\
\hline Pyridaben & Insecticide/mitochondrial & 10 \\
\hline Tolfenpyrad & Insecticide/mitochondrial & 10 \\
\hline Fenazaquin & Insecticide/mitochondrial & 10 \\
\hline Imidacloprid & Insecticide/non-mitochondrial & 60 \\
\hline Deltamethrin & Insecticide/non-mitochondrial & 40 \\
\hline Malathion & Insecticide/non-mitochondrial & 60 \\
\hline Metribuzin & Herbicide/non-mitochondrial & 40 \\
\hline Penconazole & Fungicide/non-mitochondrial & 40 \\
\hline Cypermethrin & Insecticide/non-mitochondrial & 40 \\
\hline Esfenvalerate & Insecticide/non-mitochondrial & 40 \\
\hline
\end{tabular}

Table 1. Concentration of pesticides in the oxygraph chamber/cuvette.

Hydrogen peroxide production by the mitochondria. Was measured with the Amplex Red Ultra dye (Sigma, CШA) as described early ${ }^{81}$ using a Hitachi F-7000 spectrofluorimeter in $1 \mathrm{ml}$ of the incubation medium (see above) containing $2 \mu \mathrm{M}$ Amplex Red Ultra, 100-200 $\mu \mathrm{g}$ of mitochondria, and $1 \mathrm{mg} / \mathrm{ml}$ horseradish peroxidase (excitation wavelength, $568 \mathrm{~nm}$; emission wavelength, $581 \mathrm{~nm}$ ). MB was added directly to the cuvette to the concentration of $2 \mu \mathrm{M}$. The pesticide concentration was the same as in the assessment of mitochondrial respiration (Table 1). The effect of MB and each of the pesticides on mitochondrial hydrogen peroxide production was measured in 6 repetitions $(n=6)$.

Statistical analysis. Was performed with the STATISTICA software (StatSoft Inc., Tulsa, OK, USA). The results were expressed as mean $\pm \mathrm{SD}$. The differences were analyzed with ANOVA and were considered significant at $p<0.05$. The effect of MB and each of the pesticides was measured in 6 repetitions $(n=6)$.

Results

Effect of mitochondria-targeted pesticides and MB on the mitochondria. The respiration of mitochondria from the bumble bee flight muscles on various respiratory substrates (malate, pyruvate, glutamate, proline, succinate, a-glycerophosphate) was measured in the presence and absence of $\mathrm{MB}$. We found that $\mathrm{MB}$ stimulated mitochondrial respiration mediated by Complex I on the following respiratory substrates: pyruvate, malate, pyruvate + malate, pyruvate + proline, pyruvate + glutamate. The highest respiratory rate (in the presence of ADP) was observed on pyruvate + glutamate (respiratory control, 6.1); however, the highest respiratory control (14.1) was observed on pyruvate. Thus, the respiratory rate on pyruvate in the absence of MB was $91.51 \pm 5.2 \mathrm{nmol} \mathrm{O}_{2} / \mathrm{min} \mathrm{mg}$ protein and increased to $115.30 \pm 7.21 \mathrm{nmol} \mathrm{O}_{2} / \mathrm{min} \mathrm{mg}$ protein after MB addition. At the same time, $\mathrm{MB}$ failed to stimulate mitochondrial respiration on succinate and $\alpha$-glycerophosphate.

We also studied the effect of $\mathrm{MB}$ on the respiration of mitochondria treated with the mitochondria-targeted pesticides chlorfenapyr, hydramethylnon, pyridaben, tolfenpyrad, and fenazaquin (Sigma-Aldrich, USA).

All mitochondria-targeted pesticides inhibited respiration mediated by Complex I (Fig. 1), which was then restored by the addition of MB.

Both $\mathrm{MB}$ and pesticides produced a statistically significant effect on the mitochondrial respiration: fenazaquin $\mathrm{F}(2,15)=138.82, \mathrm{p}<0.001$; tolfenpyrad $\mathrm{F}(2,15)=128.68, \mathrm{p}<0.001$; hydramethylnon $\mathrm{F}(2,15)=142.52, \mathrm{p}<0.001$; chlorfenapyr $\mathrm{F}(2,15)=142.30$, $\mathrm{p}<0.001$; pyridaben $\mathrm{F}(2,15)=289.15, \mathrm{p}<0.001$. The most pronounced inhibitory effect was observed for fenazaquin (from $90.6 \pm 9.7$ to $10.7 \pm 4.2 \mathrm{nmol} \mathrm{O}_{2} / \mathrm{min} \mathrm{mg}$ protein) and pyridaben (from $90.8 \pm 5.3$ to $12.6 \pm 4.4 \mathrm{nmol} \mathrm{O}_{2} / \mathrm{min}$ mg protein) (Tukey's test, $\mathrm{p}<0.001$ ). Tolfenpyrad, hydramethylnon, and chlorfenapyr suppressed respiration mediated by Complex I to a lesser extent (Tukey's test, $\mathrm{p}<0.001$ ). MB activated pesticide-inhibited mitochondrial respiration on pyruvate. Thus, $2 \mu \mathrm{M} M B$ increased the respiration rate inhibited by fenazaquin from $10.7 \pm 4.2$ to $53.7 \pm 9.8 \mathrm{nmol} \mathrm{O}_{2} / \mathrm{min} \mathrm{mg}$ protein (Tukey's test, $\mathrm{p}<0.001$ ). Addition of $\mathrm{MB}$ to the mitochondria inhibited by tolfenpyrad increased oxygen consumption from $16.8 \pm 6.3$ to $84.3 \pm 9.5 \mathrm{nmol} \mathrm{O}_{2} / \mathrm{min} \mathrm{mg}$ protein (Tukey's test, $\mathrm{p}<0.001$ ). In the cases of pyridaben and hydramethylnon, $\mathrm{MB}$ increased the respiration rate from $12.6 \pm 4.4$ to $46.1 \pm 7.0 \mathrm{nmol} \mathrm{O}_{2} / \mathrm{min} \mathrm{mg}$ protein and from $22.2 \pm 6.1$ to $68.7 \pm 8.3 \mathrm{nmol} \mathrm{O}_{2} / \mathrm{min} \mathrm{mg}$ protein, respectively (Tukey's test, $\mathrm{p}<0.001$ ). $\mathrm{MB}$ addition to the mitochondria inhibited with chlorfenapyr, increased the respiration rate from $18.5 \pm 5.6$ to $37.2 \pm 10.0 \mathrm{nmol} \mathrm{O} / \mathrm{min} \mathrm{mg}$ protein (Tukey's test, $\mathrm{p}<0.01$ ). Therefore, $\mathrm{MB}$ restored mitochondrial respiration suppressed by the pesticides inhibiting Complex 1 of the ETC.

Next, we estimated the effect of MB and pesticides on the generation of reactive oxygen species (ROS) by the flight muscle mitochondria in vitro. The rate of ROS production was measured on two substrates: pyruvate (respiration mediated by Complex I) and $\alpha$-glycerophosphate (respiration mediated by the mitochondrial a-glycerophosphate dehydrogenase). We found that MB did not affect the rate of ROS generation by the mitochondria on pyruvate; the production of hydrogen peroxide in the presence $\mathrm{MB}$ was $0.9 \pm 0.08 \mathrm{nmol} \mathrm{H}_{2} \mathrm{O}_{2}$ / min mg protein vs. $0.8 \pm 0.10 \mathrm{nmol} \mathrm{H}_{2} \mathrm{O}_{2} / \mathrm{min} \mathrm{mg}$ protein in the absence of $\mathrm{MB}$. Fenazaquin $(\mathrm{F}(2,15)=33.39$, $\mathrm{p}<0.001)$, tolfenpyrad $(\mathrm{F}(2,15)=23.39, \mathrm{p}<0.001)$ and pyridaben $(\mathrm{F}(2,15)=47.31, \mathrm{p}<0.001)$ have increased the 


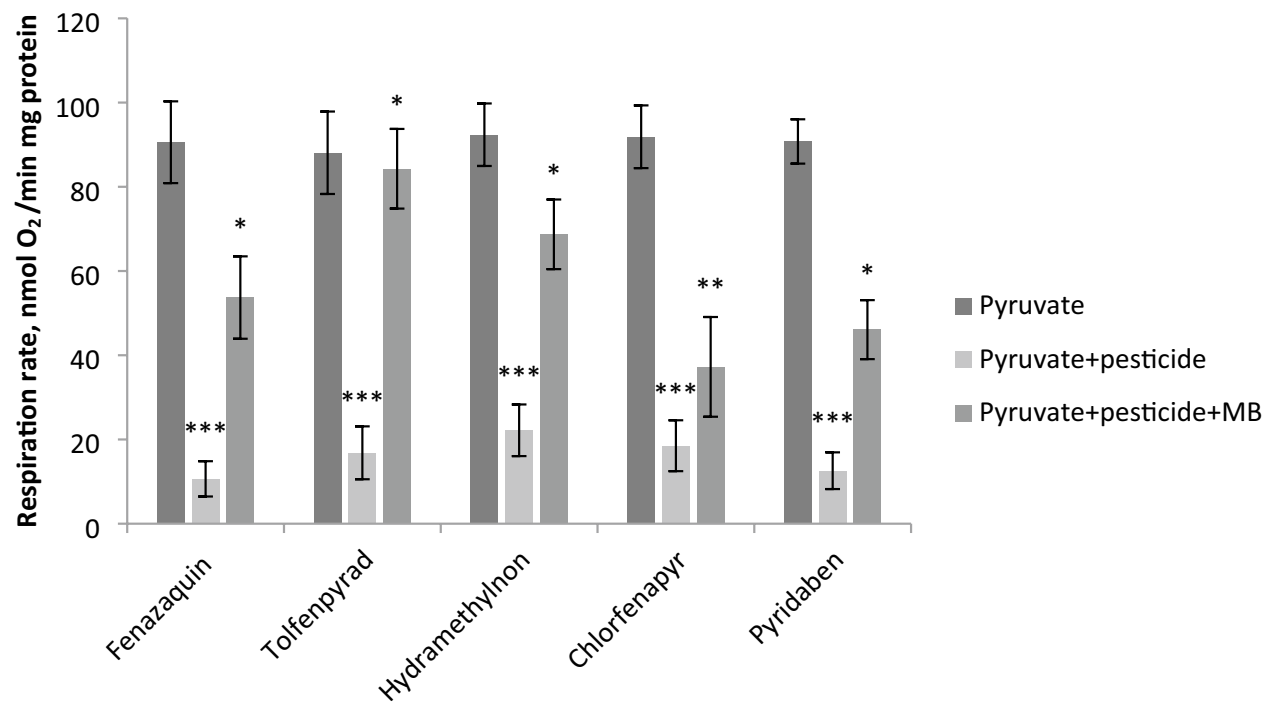

Figure 1. Respiration of mitochondria on pyruvate (ETC complex I substrate) in the presence of mitochondriatargeted pesticides and after $\mathrm{MB}$ addition (the data are shown as mean $\pm \mathrm{SD}, n=6$ ). Pesticides, $\mathrm{MB}$ and mitochondria $(120 \mu \mathrm{g})$ were directly added to the oxygraph chamber. MB was added to the concentration of $2 \mu \mathrm{M}$. The concentration of the pesticides in oxygraph chamber see in Table $1{ }^{*}$ Statistically significant differences in the mitochondrial respiration rate in the presence of pesticide and pesticide $+M B, p<0.001$. ** Statistically significant differences in the mitochondrial respiration rate in the presence of pesticide and pesticide $+\mathrm{MB}, \mathrm{p}<0.01{ }^{* * *}$ Statistically significant differences in the mitochondrial respiration rate in the absence and presence of pesticide, $\mathrm{p}<0.001$.

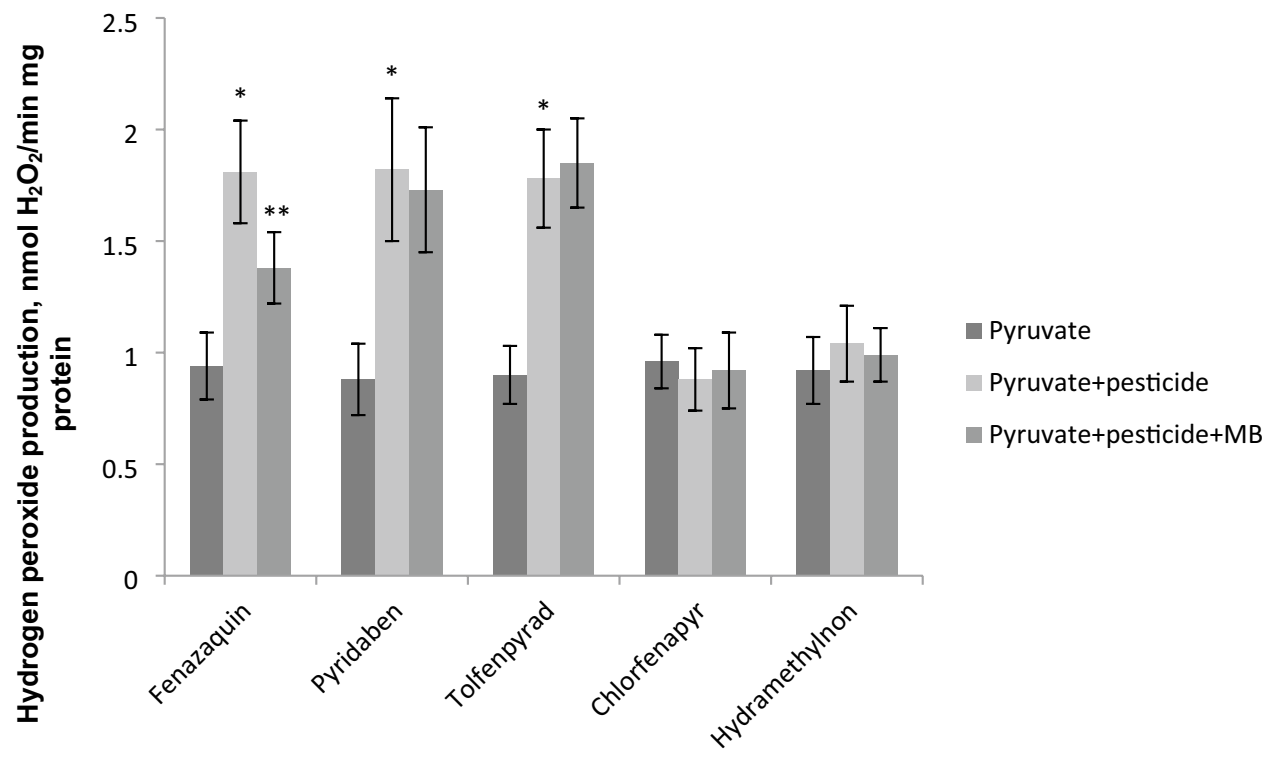

Figure 2. Hydrogen peroxide production of mitochondria on pyruvate (ETC complex I substrate) in the presence of mitochondria-targeted pesticides and after MB addition (the data are shown as mean $\pm \mathrm{SD}, n=6$ ). Pesticides, $\mathrm{MB}$ and mitochondria were directly added to the cuvette. MB was added to the concentration of $2 \mu \mathrm{M}$. The concentration of the pesticides in cuvette see in Table $1 .{ }^{*}$ Statistically significant differences in the hydrogen peroxide production of mitochondria in the absence and presence of pesticide, $p<0.001$. ${ }^{* *}$ Statistically significant differences in the hydrogen peroxide production of mitochondria in the presence of pesticide and pesticide $+\mathrm{MB}, \mathrm{p}<0.01$. 
A

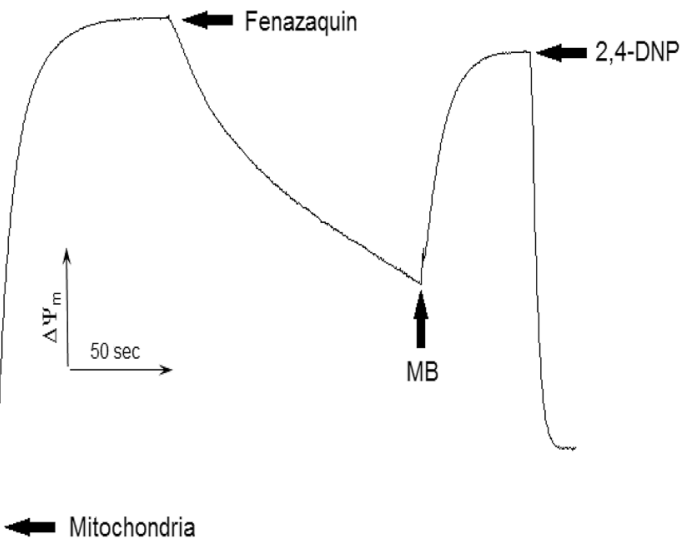

B

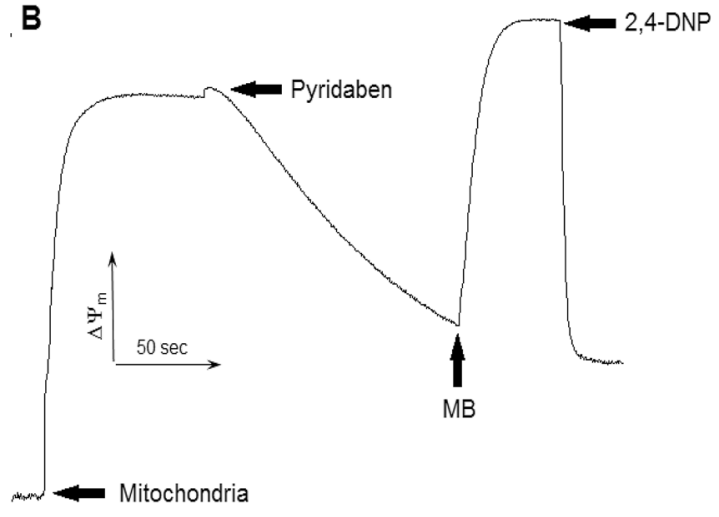

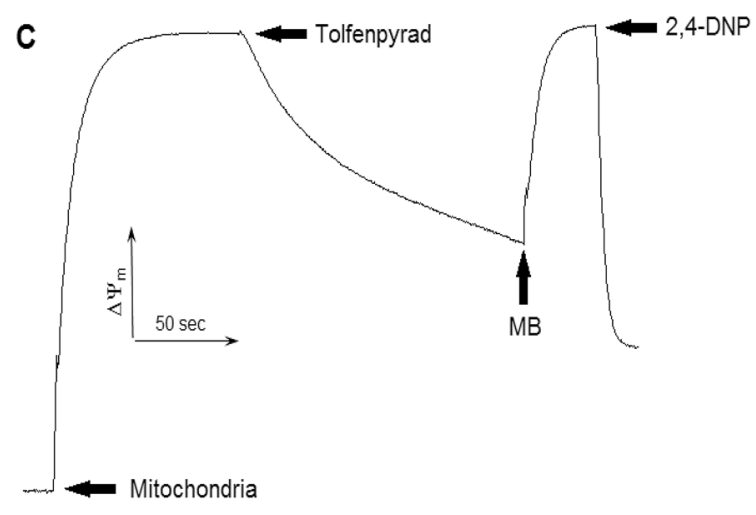

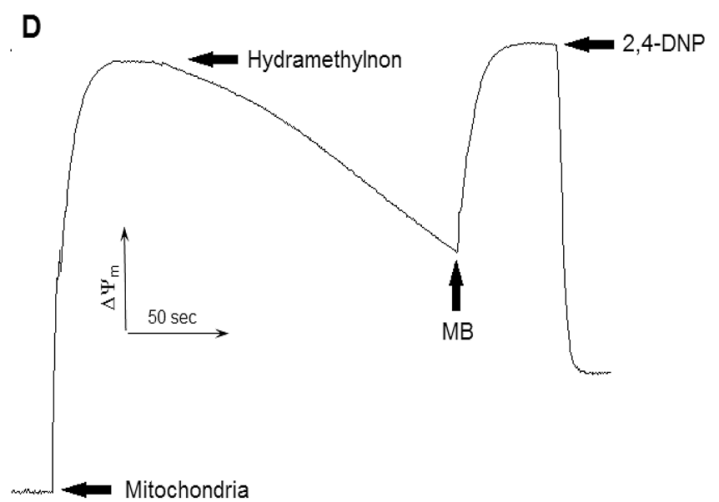

$\mathbf{E}$

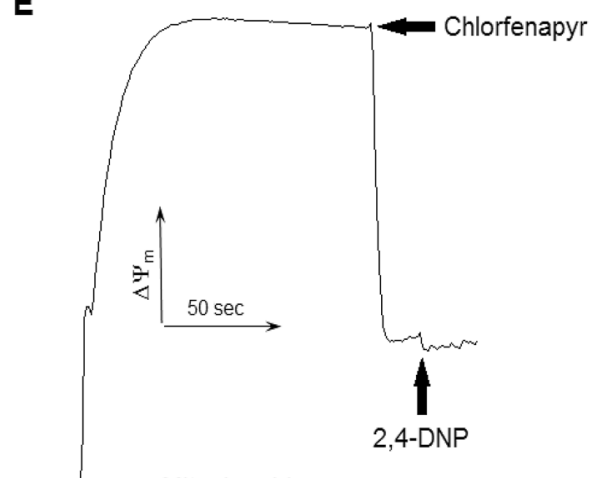

$\mathbf{F}$

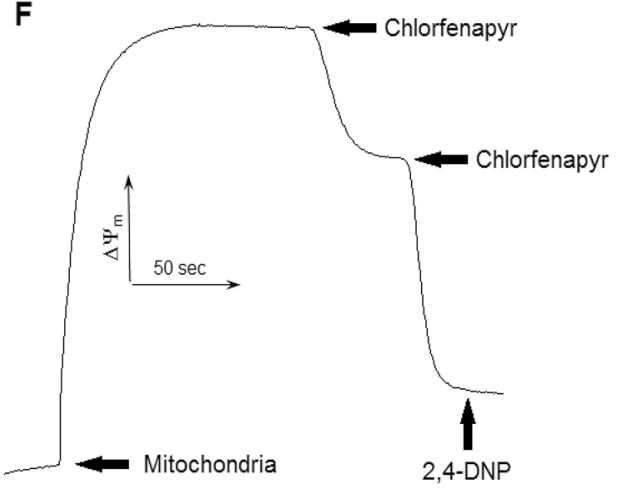

Figure 3. $\mathrm{MB}$ restored mitochondrial membrane potential on glutamate + pyruvate (ETC complex I substrate) after dissipation by fenazaquin (A), pyridaben (B), tolfenpyrad (C), and hydramethylnon (D). Chlorfenapyr uncoupled mitochondrial respiration on both glutamate + pyruvate $(\mathbf{E})$ and $\alpha$-glycerophosphate $(\mathbf{F}) ; 2,4$-DNP, 2,4-dinitrophenol. Pesticides, $\mathrm{MB}$ and mitochondria were directly added to the cuvette. MB was added to the concentration of $2 \mu \mathrm{M}$. The concentration of the pesticide in cuvette see in Table $1, n=6$.

production of hydrogen peroxide on the pyruvate (Fig. 2). No differences in the $\mathrm{H}_{2} \mathrm{O}_{2}$ production before and after $\mathrm{MB}$ and pesticide addition were found in the mitochondria on a-glycerophosphate $\left(3.1 \pm 0.27 \mathrm{H}_{2} \mathrm{O}_{2} / \mathrm{min}\right.$ mg protein in the absence of $\mathrm{MB}$ vs. $3.5 \pm 0.32 \mathrm{H}_{2} \mathrm{O}_{2} / \mathrm{min} \mathrm{mg}$ protein in the presence of $\mathrm{MB}$ ).

After fenazaquin $\mathrm{MB}$ reduced the production of hydrogen peroxide by mitochondria from $1,81 \pm 0,23$ to $1,38 \pm 0,16 \mathrm{nmol} \mathrm{H}_{2} \mathrm{O}_{2} / \mathrm{min} \mathrm{mg}$ protein (Tukey's test, $\mathrm{p}<0.01$ ). MB did not reduce or increase production of hydrogen peroxide by mitochondria after other pesticides.

MB restored the mitochondrial membrane potential dissipated by the pesticides affecting the ETC (Fig. 3).

Therefore, $\mathrm{MB}$ was able to restore both mitochondrial respiration and mitochondrial membrane potential necessary for the ATP production in the mitochondria. We also found that chlorfenapyr uncoupled mitochondrial 


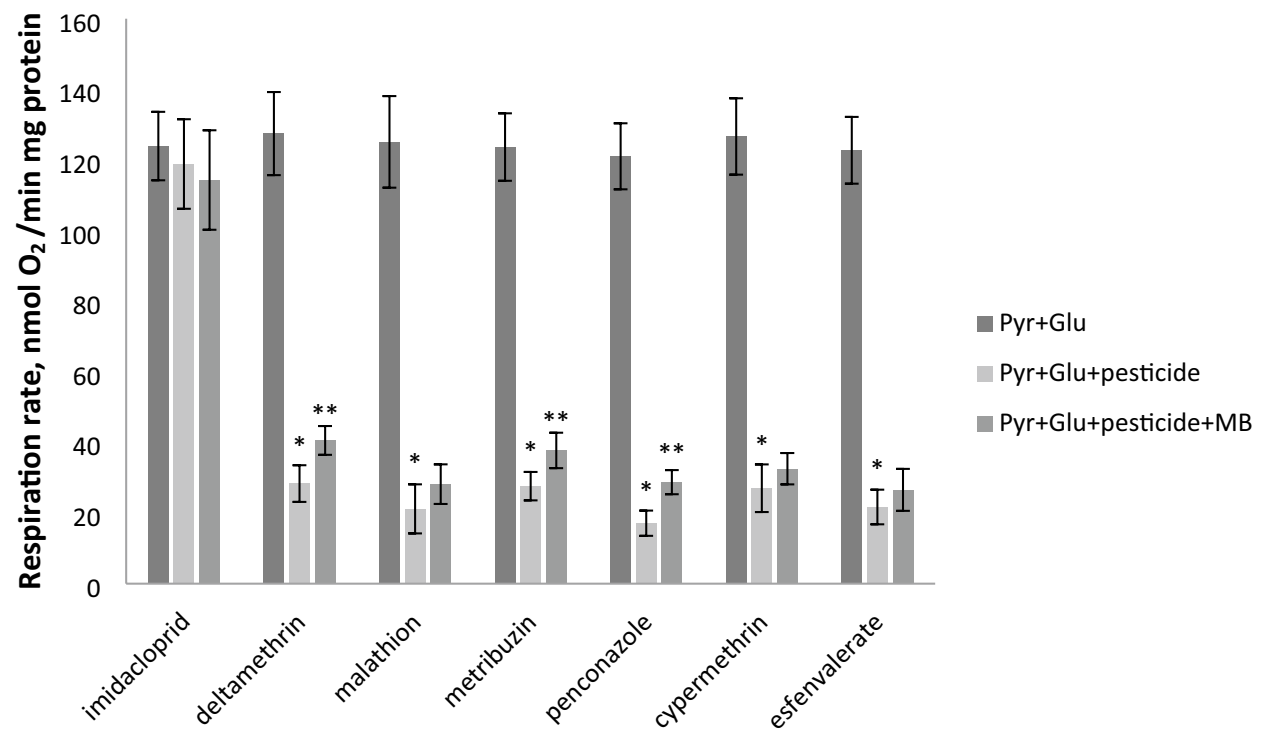

Figure 4. Effect of pesticides and $\mathrm{MB}$ on the mitochondrial respiration on ETC complex I substrates (the data are shown as mean \pm SD, $n=6$ ); Pyr pyruvate, Glu glutamate. Pesticides, MB and mitochondria (120 $\mu$ g) were directly added to the oxygraph chamber. $\mathrm{MB}$ was added to the concentration of $2 \mu \mathrm{M}$. The concentration of the pesticide in oxygraph chamber see in Table $1, n=6$. ${ }^{*}$ Statistically significant differences in the mitochondrial respiration rate in the absence and presence of pesticide, $\mathrm{p}<0.001 .{ }^{*}$ Statistically significant differences in the mitochondrial respiration rate in the presence of pesticide and pesticide $+\mathrm{MB}, \mathrm{p}<0.05$.

respiration, since its addition to the mitochondria oxidizing a-glycerophosphate (Fig. 3F) led to the complete loss of membrane potential.

Effect of non-mitochondrial pesticides and MB on the mitochondria. We also evaluated the respiration rate of the isolated flight muscle mitochondria on glutamate + pyruvate (respiration mediated by Complex I) in the presence of ADP after incubation with the pesticides imidacloprid, deltamethrin, malathion, metribuzin, penconazole, cypermethrin, and esfenvalerate and following addition of MB. The components of the reaction mixture were added to the oxygraph cell in the following order: mitochondria, ADP, pesticide, MB. The effect of the pesticides and MB on the mitochondrial respiration is shown in Fig. 4.

The effect of pesticides (except imidacloprid) and MB on the mitochondrial respiration was statistically significant: deltamethrin $\mathrm{F}(2,15)=288.77, \mathrm{p}<0.001$; malathion $\mathrm{F}(2,15)=244.90, \mathrm{p}<0.001$; metribuzin $\mathrm{F}(2,15)=377.70$, $\mathrm{p}<0.001$; penconazole $\mathrm{F}(2,15)=517.61, \mathrm{p}<0.001$; cypermethrin $\mathrm{F}(2,15)=311.68, \mathrm{p}<0.001$; esfenvalerate $\mathrm{F}(2$, $15)=392.78, \mathrm{p}<0.001$. Deltamethrin noticeably (from $127.5 \pm 11.8$ to $28.4 \pm 5.2 \mathrm{nmol} \mathrm{O} / \mathrm{min} \mathrm{mg}$ protein) inhibited mitochondrial respiration (Tukey's test, $\mathrm{p}<0.001$ ); subsequent addition of MB stimulated respiration to $40.6 \pm 4.1 \mathrm{nmol} \mathrm{O} / \mathrm{min} \mathrm{mg}$ protein (Tukey's test, $\mathrm{p}<0.05$ ). Metribuzin inhibited respiration from $123.7 \pm 9.6$ to $27.6 \pm 4.0 \mathrm{nmol} \mathrm{O} / \mathrm{min} \mathrm{mg}$ protein (Tukey's test, $\mathrm{p}<0.001$ ); $\mathrm{MB}$ increased respiration to $37.7 \pm 5.0 \mathrm{nmol} \mathrm{O}_{2} / \mathrm{min}$ mg protein (Tukey's test, $\mathrm{p}<0.05$ ). Penconazole inhibited respiration from $121.0 \pm 9.4$ to $17.1 \pm 3.6 \mathrm{nmol} \mathrm{O}_{2} /$ min mg protein (Tukey's test, $\mathrm{p}<0.001$ ), while $\mathrm{MB}$ stimulated respiration to $28.8 \pm 3.4 \mathrm{nmol} \mathrm{O}_{2} / \mathrm{min}$ mg protein (Tukey's test, $\mathrm{p}<0.05$ ). Cypermethrin and esfenvalerate suppressed mitochondrial respiration from $126.7 \pm 10.8$ to $27.0 \pm 6.8 \mathrm{nmol} \mathrm{O}_{2} / \mathrm{min} \mathrm{mg}$ protein (Tukey's test, $\mathrm{p}<0.001$ ) and from $122.7 \pm 9.5$ to $21.7 \pm 4.9 \mathrm{nmol} \mathrm{O} / \mathrm{min} \mathrm{mg}$ protein (Tukey's test, $\mathrm{p}<0.001$ ), respectively; in both cases, the following addition of MB failed to increase the respiration rate. Hence, $\mathrm{MB}$ partially restored mitochondrial respiration suppressed by deltamethrin, metribuzin and penconazole (pesticides affecting Complex 1). No differences in the $\mathrm{H}_{2} \mathrm{O}_{2}$ production before and after nonmitochondrial pesticide addition were found in the mitochondria.

\section{Discussion}

Here, we demonstrated that MB stimulates respiration mediated by Complex I of the ETC in the mitochondria from the bumble bee flight muscles. Note that no stimulation of mitochondrial respiration was observed on a-glycerophosphate or succinate, as respiration on these two substrates is not mediated by Complex I. Presumably, MB acts as a redox component of the ETC due to its ability to participate in the NADH oxidation by Complex I and to transfer electrons on cytochrome $c$, thus providing an alternative electron transfer in the mitochondria.

$\mathrm{MB}$ addition caused no statistically significant changes in the rates of ROS production by the mitochondria on $\alpha$-glycerophosphate and pyruvate, which might be explained by the presumed MB ability to shunt electrons in Complex I, thus ensuring partial reduction of the electron flow through NADH dehydrogenase, which contributes most to the ROS generation.

$M B$ restored respiration in the mitochondria treated with the mitochondria-targeted pesticides, such as pyridaben, chlorfenapyr, fenazaquin, tolfenpyrad, and hydramethylnon. As reported earlier, chlorfenapyr disturbs 
oxidative phosphorylation in the mitochondria ${ }^{44}$ (uncouples oxidative phosphorylation and suppresses ATP production), which might result in the organism death. According to our data, chlorfenapyr inhibited Complex I in the bumble bee flight muscle mitochondria. It also increased the mitochondrial respiration rate on a-glycerophosphate (unpublished data), which was most probably due to the uncoupling effect of this compound. These data confirm our hypothesis that chlorfenapyr uncouples oxidative phosphorylation, as well as inhibits Complex I in the bumble bee flight muscle mitochondria.

Hydramethylnon is known to suppress the activity of Complex III of the mitochondrial ETC ${ }^{41}$. We found that that this pesticide indeed inhibited Complex III, because it decreased (1.3 times) the respiration rate on both pyruvate and $\alpha$-glycerophosphate. However, inhibition by hydramethylnon was more pronounced for the respiration on pyruvate (see above), which suggests that this pesticide inhibited both Complex I and Complex III in the flight muscle mitochondria.

The mechanism of $\mathrm{MB}$ action as an antidote might be related to the specific properties of this compound. MB has been long known as an electron carrier ${ }^{82,83}$. It is also a redox mediator capable of oxidizing intramitochondrial $\mathrm{NADH}$ and transferring electrons to the downstream components of the ETC. This effect was termed "alternative electron transport" ${ }^{84}$. $\mathrm{MB}$ can be reduced by $\mathrm{NADH}, \mathrm{FADH}_{2}$, and a-glycerophosphate to leucomethylene blue $(\mathrm{MBH} 2)$, which is then oxidized primarily by cytochrome $c^{85}$. This suggests that MB donates electrons to the Qo ubiquinol-binding site of Complex III.

We have shown earlier that a wide range of pesticides, including non-mitochondrial ones, negatively affect the bioenergetic parameters of mitochondria from the bumble bee flight muscles ${ }^{86}$. Interestingly, MB also stimulated respiration after treatment of the mitochondria with the non-mitochondrial pesticides, such as deltamethrin, metribuzin and penconazole, although to a lesser extent than after the treatment with the mitochondria-targeted pesticides. It is possible that MB can act as an antidote against other (non-mitochondrial) pesticides, but this hypothesis requires further investigation.

The mechanism of the MB-mediated stimulation of respiration in the mitochondria from the bumble bee flight muscles after exposure to pesticides remains unclear. Most probably, the activity of MB is related to its ability to shunt electrons in the mitochondrial ETC. Although further studies are required for the comprehensive understanding of the $\mathrm{MB}$ action mechanisms, the obtained results already suggest that $\mathrm{MB}$ can be used as an antidote against the toxic action of pesticides in pollinators.

\section{Conclusions}

MB stimulated respiration mediated by Complex I in the bumble bee flight muscles mitochondria and restored respiration in the mitochondria treated with the mitochondria-targeted pesticides, such as pyridaben, chlorfenapyr, fenazaquin, tolfenpyrad, and hydramethylnon. MB also stimulated respiration in the mitochondria subjected to the action of non-mitochondrial pesticides, such as deltamethrin, metribuzin and penconazole, although to a lesser extent than in the mitochondria treated with the mitochondria-targeted pesticides. MB restored the mitochondrial membrane potential dissipated by the pesticides affecting the ETC. Taken together, these data demonstrate that $\mathrm{MB}$ can be used to reduce the toxicity of pesticides in pollinators. For instance, MB can be added to the syrup used for feeding bumble bees, which might be convenient for the insect treatment in both indoor (greenhouses) and outdoor environments. However, further studies on the effects of MB on bumble bees and other pollinators are needed to elucidate the precise mechanism of action of this antidote.

Received: 13 April 2021; Accepted: 7 July 2021

Published online: 19 July 2021

\section{References}

1. Potts, S. G. et al. Global pollinator declines: Trends, impacts and drivers. Trends Ecol. Evol. 25, 345-353 (2010).

2. Biesmeijer, J. C. et al. Parallel declines in pollinators and insect-pollinated plants in Britain and the Netherlands. Science $\mathbf{3 1 3}$, 351-354 (2006).

3. Rhodes, C. J. Pollinator decline-an ecological calamity in the making?. Sci. Prog. 101, 121-160 (2018).

4. Thomann, M., Imbert, E., Devaux, C. \& Cheptou, P.-O. Flowering plants under global pollinator decline. Trends Plant Sci. 18, 353-359 (2013).

5. Connelly, H., Poveda, K. \& Loeb, G. Landscape simplification decreases wild bee pollination services to strawberry. Agr. Ecosyst. Environ. 211, 51-56 (2015).

6. Goulson, D., Lye, G. C. \& Darvill, B. Decline and conservation of bumble bees. Annu. Rev. Entomol. 53, 191-208 (2008).

7. Velthuis, H. H. W. \& van Doorn, A. A century of advances in bumble bee domestication and the economic and environmental aspects of its commercialization for pollination. Apidologie 37, 421-451 (2006).

8. Cameron, S. A. et al. Patterns of widespread decline in North American bumble bees. Proc. Natl. Acad. Sci. USA 108, 662-667 (2011).

9. Colla, S. R. \& Packer, L. Evidence for decline in eastern North American bumble bees (Hymenoptera: Apidae), with special focus on Bombus affinis Cresson. Biodivers. Conserv. 17, 1379-1391 (2008).

10. Grixti, J. C., Wong, L. T., Cameron, S. A. \& Favret, C. Decline of bumble bees (Bombus) in the North American Midwest. Biol. Cons. 142, 75-84 (2009).

11. Lu, C., Warchol, K. M. \& Callahan, R. A. Sub-lethal exposure to neonicotinoids impaired honey bees winterization before proceeding to colony collapse disorder. Bull. Insectol. 67, 125-130 (2014).

12. van der Sluijs, J. P. et al. Neonicotinoids, bee disorders and the sustainability of pollinator services. Curr. Opin. Environ. Sustain. 5, 293-305 (2013).

13. Simon-Delso, N. et al. Systemic insecticides (neonicotinoids and fipronil): Trends, uses, mode of action and metabolites. Environ. Sci. Pollut. Res. Int. 22, 5-34 (2015).

14. Bryden, J., Gill, R. J., Mitton, R. A. A., Raine, N. E. \& Jansen, V. A. A. Chronic sublethal stress causes bee colony failure. Ecol. Lett. 16, 1463-1469 (2013).

15. Brown, M. J. F. \& Paxton, R. J. The conservation of bees: A global perspective. Apidologie 40, 410-416 (2009). 
16. Brutscher, L. M., Baer, B. \& Niño, E. L. Putative drone copulation factors regulating honey bee (Apis mellifera) queen reproduction and health: A review. Insects 8, 8 (2019).

17. Vanbergen, A. J. Threats to an ecosystem service: Pressures on pollinators. Front. Ecol. Environ. 11(5), 251-259 (2013).

18. Ullah, A. et al. Viral impacts on honey bee populations: A review. Saudi J. Biol. Sci. 28, 523-530 (2021).

19. Alburaki, M. et al. Honey bee survival and pathogen prevalence: From the perspective of landscape and exposure to pesticides. Insects 9, 65 (2018)

20. Staveley, J. P., Law, S. A., Fairbrother, A. \& Menzie, C. A. A causal analysis of observed declines in managed honey bees (Apis mellifera), human and ecological risk assessment. Int. J. 20, 566-591 (2014).

21. Francis, R. M., Nielsen, S. L. \& Kryger, P. Varroa-virus interaction in collapsing honey bee colonies. PLoS ONE 8, e57540 (2013).

22. Martin, S. J. The role of Varroa and viral pathogens in the collapse of honeybee colonies: A modelling approach. J. Appl. Ecol. 38, 1082-1093 (2001).

23. Klein, S., Cabirol, A., Devaud, J. M., Barron, A. B. \& Lihoreau, M. Why bees are so vulnerable to environmental stressors. Trends Ecol. Evol. 32, 268-278 (2017).

24. Sánchez-Bayo, F. \& Wyckhuys, K. A. G. Worldwide decline of the entomofauna: A review of its drivers. Biol. Cons. 232, 8-27 (2019).

25. Flores, J. M. et al. of the climate change on honey bee colonies in a temperate Mediterranean zone assessed through remote hive weight monitoring system in conjunction with exhaustive colonies assessment. Sci. Total Environ. 653, 1111-1119 (2019).

26. Becher, M. A. et al. BEEHAVE: A systems model of honeybee colony dynamics and foraging to explore multifactorial causes of colony failure. J. Appl. Ecol. 51, 470-482 (2014).

27. Branchiccela, B. et al. Impact of nutritional stress on the honeybee colony health. Sci. Rep. 9, 10156 (2019).

28. Carreck, N. The appliance of science. Bee World 89, 10-11 (2012).

29. Goulson, D., Nicholls, E., Botías, C. \& Rotheray, E. L. Bee declines driven by combined stress from parasites, pesticides, and lack of flowers. Science 347, 1255957 (2015).

30. Oneal, S. T., Anderson, T. D. \& Wu-Smart, J. Y. Interactions between pesticides and pathogen susceptibility in honey bees. Curr. Opin. Insect Sci. 26, 57-62 (2018).

31. Grass, J. et al. Synergistic effects of pathogen and pesticide exposure on honey bee (Apis mellifera) survival and immunity. J. Invertebr Pathol. 159, 78-86 (2018).

32. Woodcock, B. et al. Impacts of neonicotinoid use on long-term population changes in wild bees in England. Nat. Commun. 7, 12459 (2016).

33. Woodcock, B. A. et al. Country-specific effects of neonicotinoid pesticides on honey bees and wild bees. Science 356, 1393-1395 (2017).

34. Fisher, A. II., Coleman, C., Hoffmann, C., Fritz, B. \& Rangel, J. The synergistic effects of almond protection fungicides on honey bee (Hymenoptera: Apidae) forager survival. J. Econ. Entomol. 110, 802-808 (2017).

35. Raimets, R. et al. Synergistic interactions between a variety of insecticides and an ergosterol biosynthesis inhibitor fungicide in dietary exposures of bumble bees (Bombus terrestris L.). Pest Manag. Sci. 74, 541-546 (2018).

36. Zhu, Y. C., Yao, J., Adamczyk, J. \& Luttrell, R. Synergistic toxicity and physiological impact of imidacloprid alone and binary mixtures with seven representative pesticides on honeybee (Apis mellifera). PLoS ONE 12, e0176837 (2017).

37. Sgolastra, F. et al. Synergistic mortality between a neonicotinoid insecticide and an ergosterol-biosynthesis-inhibiting fungicide in three bee species. Pest Manag. Sci. 73, 1236-1243 (2017).

38. Baron, G. L., Raine, N. E. \& Brown, M. J. F. General and species-specific impacts of a neonicotinoid insecticide on the ovary development and feeding of wild bumblebee queens. Proc. Biol. Sci. 284, 20170123 (2017).

39. Maini, S., Medrzycki, P. \& Porrini, C. The puzzle of honey bee losses: A brief review. Bull. Insectol. 63(1), 153-160 (2010).

40. Strain, G. M. Evoked potential and EEG study of the neurotoxicity of hydramethylnon in rats. Res. Vet. Sci. 124, 452-460 (2019).

41. Hollingshaus, G. J. Inhibition of mitochondrial electron transport by hydramethylnon: A new amidinohydrazone insecticide. Pestic. Biochem. Physiol. 27, 61-70 (1987).

42. Charli, A., Jin, H., Anantharam, V., Kanthasamy, A. \& Kanthasamy, A. G. Alterations in mitochondrial dynamics induced by tebufenpyrad and pyridaben in a dopaminergic neuronal cell culture model. Neurotoxicology 53, 302-313 (2011).

43. Lees, R. S. et al. New insecticide screening platforms indicate that Mitochondrial Complex I inhibitors are susceptible to crossresistance by mosquito P450s that metabolise pyrethroids. Sci. Rep. 10, 16232 (2020).

44. Raghavendra, K. et al. Chlorfenapyr: A new insecticide with novel mode of action can control pyrethroid resistant malaria vectors. Malar. J. 10, 16 (2011).

45. Campbell, J. B. et al. The fungicide Pristine inhibits mitochondrial function in vitro but not flight metabolic rates in honey bees. J. Insect. Physiol. 86, 11-16 (2016).

46. Nicodemo, D. et al. Fipronil and imidacloprid reduce honeybee mitochondrial activity. Environ. Toxicol. Chem. 33, 2070-2075 (2014).

47. Farkhondeh, T., Mehrpour, O., Forouzanfar, F., Roshanravan, B. \& Samarghandian, S. Oxidative stress and mitochondrial dysfunction in organophosphate pesticide-induced neurotoxicity and its amelioration: a review. Environ. Sci. Pollut. Res. Int. 27, 24799-24814 (2020)

48. Guven, C., Sevgiler, Y. \& Taskin, E. Pyrethroid insecticides as the mitochondrial dysfunction inducers. IntechOpen 12, 293-322 (2018).

49. Liu, Q. et al. Organochloride pesticides impaired mitochondrial function in hepatocytes and aggravated disorders of fatty acid metabolism. Sci. Rep. 7, 46339 (2017).

50. Fent, K., Schmid, M., Hettich, T. \& Schmid, S. The neonicotinoid thiacloprid causes transcriptional alteration of genes associated with mitochondria at environmental concentrations in honey bees. Environ. Pollut. 266, 115297 (2020).

51. Syromyatnikov, M. Y. et al. Evaluation of the toxicity of fungicides to flight muscle mitochondria of bumblebee (Bombus terrestris L.). Pesticide Biochem. Physiol. 135, 41-46 (2020).

52. Powner, M. B., Salt, T. E., Hogg, C. \& Jeffery, G. Improving mitochondrial function protects bumblebees from neonicotinoid pesticides. PLOS ONE 11, e0166531 (2016).

53. Xu, Y.-G. \& Lu, Y.-Q. Systematic review and meta-analysis of the efficacy and safety of immunosuppressive pulse therapy in the treatment of paraquat poisoning. J. Zhejiang Univ. Sci. B. 20, 588-597 (2019).

54. Junbo, Z. et al. Experimental study of sucralfate intervention for paraquat poisoning in rats. Environ. Toxicol. Pharmacol. 53, 57-63 (2017).

55. Silfeler, I. et al. Protective effect of ellagic acid on paraquat-induced kidney hazards in rats. Iran J. Kidney Dis. 11, 23-28 (2017).

56. Baltazar, M. T. et al. New formulation of paraquat with lysine acetylsalicylate with low mammalian toxicity and effective herbicidal activity. Pest Manag. Sci. 69, 553-558 (2013).

57. Roberts, D. M. \& Aaron, C. K. Management of acute organophosphorus pesticide poisoning. BMJ 334, 629-634 (2007).

58. Konickx, L. A., Bingham, K. \& Eddleston, M. Is oxygen required before atropine administration in organophosphorus or carbamate pesticide poisoning?-A cohort study. Clin. Toxicol. (Phila). 52, 531-537 (2014).

59. Eddleston, M., Buckley, N., Eyer, P. \& Dawson, A. H. Management of acute organophosphorus pesticide poisoning. Lancet 371, 597-607 (2008).

60. Eddleston, M. \& Chowdhury, F. R. Pharmacological treatment of organophosphorus insecticide poisoning: the old and the (possible) new. Br. J. Clin. Pharmacol. 81, 462-470 (2016). 
61. Gorecki, L. et al. SAR study to find optimal cholinesterase reactivator against organophosphorous nerve agents and pesticides. Arch. Toxicol. 90, 2831-2859 (2016).

62. Buckley, N. A., Eddleston, M. \& Szinicz, L. Oximes for acute organophosphate pesticide poisoning. Cochrane Database Syst Rev. 1, CD005085 (2005).

63. Snider, T. H., Babin, M. C., Jett, D. A., Platoff, G. E. Jr. \& Yeung, D. T. Toxicity and median effective doses of oxime therapies against percutaneous organophosphorus pesticide and nerve agent challenges in the Hartley guinea pig. J. Toxicol. Sci. 41, 511-521 (2016).

64. Pajoumand, A., Shadnia, S., Rezaie, A., Abdi, M. \& Abdollahi, M. Benefits of magnesium sulfate in the management of acute human poisoning by organophosphorus insecticides. Hum. Exp. Toxicol. 23, 565-569 (2004).

65. Goel, A. \& Aggarwal, P. Pesticide poisoning. Natl. Med. J. India. 20, 182-191 (2007).

66. Leveau, P. Acute poisoning by pesticides in children. Arch. Pediatr. 23, 775-780 (2016).

67. Gallori, E., Casalone, E., Colella, C. M., Daly, S. \& Polsinelli, M. 1,8-Naphthalic anhydride antidote enhances the toxic effects of captan and thiram fungicides on Azospirillum brasilense cells. Res. Microbiol. 142, 1005-1012 (1991).

68. Souza, L. P. et al. Ozone treatment for pesticide removal from carrots: Optimization by response surface methodology. Food Chem. 243, 435-441 (2018).

69. Greenberg, M. Methylene blue: Fast-acting antidote for methemoglobinemia. Emerg. Med. News 23, 26 (2001).

70. Jaffe, E. R. \& Neurmann, G.A comparision of the effect of menadione, methylene blue and ascorbic acid on the reduction of methemoglobin in vivo. Nature 202, 607-8 (1964).

71. Brooks, M. M. Methylene blue as antidote for cyanide and carbon monoxide poisoning. JAMA 100, 59 (1933).

72. Draize, J. H. Sodium tetrathionate and methylene blue in cyanide and carbon monoxide poisoning. Science 78, 145 (1933).

73. Tucker, D., Lu, Y. \& Zhang, Q. From mitochondrial function to neuroprotection-An emerging role for methylene blue. Mol. Neurobiol. 55, 5137-5153 (2018).

74. Pelgrims, J. et al. Methylene blue in the treatment and prevention of ifosfamide-induced encephalopathy: report of 12 cases and a review of the literature. Br. J. Cancer. 82, 291-294 (2000).

75. Duicu, O. M. et al. Methylene blue improves mitochondrial respiration and decreases oxidative stress in a substrate-dependent manner in diabetic rat hearts. Can. J. Physiol. Pharmacol. 95, 1376-1382 (2017).

76. Rojas, J. C., John, J. M., Lee, J. \& Gonzalez-Lima, F. Methylene blue provides behavioral and metabolic neuroprotection against optic neuropathy. Neurotox Res. 15, 260-273 (2009).

77. Syromyatnikov, M. Y., Lopatin, A. V., Starkov, A. A. \& Popov, V. N. Isolation and properties of flight muscle mitochondria of the bumble bee Bombus terrestris (L). Biochem. Mosc. 78, 909-914 (2013).

78. Visarius, T. M., Stucki, J. W. \& Lauterburg, B. H. Stimulation of respiration by methylene blue in rat liver mitochondria. FEBS Lett. 412, 1873-3468 (1997)

79. Gureev, A. P., Shaforostova, E. A., Popov, V. N. \& Starkov, A. A. Methylene blue does not bypass Complex III antimycin block in mouse brain mitochondria. FEBS Lett. 593, 499-503 (2019).

80. Figueira, T. R., Melo, D. R., Vercesi, A. E. \& Castilho, R. F. Safranine as a fluorescent probe for the evaluation of mitochondrial membrane potential in isolated organelles and permeabilized cells. Methods Mol. Biol. 810, 103-117 (2012).

81. Starkov, A. A. Measurement of mitochondrial ROS production. Methods Mol. Biol. 648, 245-255 (2010).

82. Atamna, H. et al. Methylene blue delays cellular senescence and enhances key mitochondrial biochemical pathways. FASEB J. 22, 703-712 (2008).

83. Lee, K. K. \& Boelsterli, U. A. Bypassing the compromised mitochondrial electron transport with methylene blue alleviates efavirenz/ isoniazid-induced oxidant stress and mitochondria-mediated cell death in mouse hepatocytes. Redox Biol. 2, 599-609 (2014).

84. Wen, Y. et al. Alternative mitochondrial electron transfer as a novel strategy for neuroprotection. J. Biol. Chem. 286, 16504-16515 (2011).

85. Tretter, L., Horvath, G., Hölgyesi, A., Essek, F. \& Adam-Vizi, V. Enhanced hydrogen peroxide generation accompanies the beneficial bioenergetic effects of methylene blue in isolated brain mitochondria. Free Radic. Biol. Med. 77, 317-330 (2014).

86. Syromyatnikov, M. Y. et al. Method for detection of mtDNA damages for evaluating of pesticides toxicity for bumble bees (Bombus terrestris L). Pesticide Biochem. Physiol. 169, 104675 (2020).

\section{Author contributions}

Conceptualization, M.S. and V.P.; experiments, E.N. and T.S.; writing-original draft preparation, M.S.; writing-review and editing, V.P. All authors have read and agreed to the published version of the manuscript.

\section{Funding}

This work was supported by Ministry of Science and Higher Education of the Russian Federation within the framework of the national project "Science" (project FZGW-2020-0001, unique State task number 075001X39782002).

\section{Competing interests}

The authors declare no competing interests.

\section{Additional information}

Correspondence and requests for materials should be addressed to M.S.

Reprints and permissions information is available at www.nature.com/reprints.

Publisher's note Springer Nature remains neutral with regard to jurisdictional claims in published maps and institutional affiliations.

Open Access This article is licensed under a Creative Commons Attribution 4.0 International License, which permits use, sharing, adaptation, distribution and reproduction in any medium or format, as long as you give appropriate credit to the original author(s) and the source, provide a link to the Creative Commons licence, and indicate if changes were made. The images or other third party material in this article are included in the article's Creative Commons licence, unless indicated otherwise in a credit line to the material. If material is not included in the article's Creative Commons licence and your intended use is not permitted by statutory regulation or exceeds the permitted use, you will need to obtain permission directly from the copyright holder. To view a copy of this licence, visit http://creativecommons.org/licenses/by/4.0/.

(C) The Author(s) 2021 